\title{
FE DE ERRATUM
}

En el artículo: "Características de la insuficiencia cardíaca en pacientes con fracción de eyección preservada: Resultados del Registro Nacional de Insuficiencia Cardíaca, Grupo ICARO", de los autores Vukasovic JL, Castro P, Sepúlveda L, Nazzal C, Garcés E, Concepción R, Soto JR, Yovaniniz P, Ferrada M, Cavada G. Rev Méd Chile 2006; 134: 539-548.

La Tabla 1. Análisis multivariado de las diferencias entre pacientes con $\mathrm{FE} \geq 50$ y FE $<50$ (página 543) debe reemplazarse por la siguiente:

\begin{tabular}{|lccr|}
\hline & Odds ratio & $\mathrm{p}$ & $\mathrm{IC} 95 \%$ \\
\hline Sexo femenino & 2,62 & 0,002 & $1,1-6,1$ \\
Hipertensión arterial & 1,43 & 0,39 & $0,6-3,2$ \\
Infarto al miocardio & 0,41 & 0,10 & $0,14-1,2$ \\
Valvulopatía & 1,9 & 0,15 & $0,7-4,7$ \\
Fibrilación auricular & 1,5 & 0,26 & $0,7-3,5$ \\
Presión sistólica al ingreso & 1,01 & 0,19 & $1,0-3,4$ \\
Presión diastólica al ingreso & 1,00 & 0,62 & $0,9-1,1$ \\
\hline
\end{tabular}

